\title{
Prevalence of gestational diabetes mellitus, its associated risk factors and pregnancy outcomes at a rural setup in Central India
}

\author{
Kanika R. Kalyani*, Shubhada Jajoo, Chella Hariharan, Swarnalata Samal
}

Department of Obstetrics and Gynaecology, Datta Meghe Institute of Medical Sciences, Wardha-442004, Maharashtra, India

Received: 18 October 2013

Accepted: 27 October 2013

\section{*Correspondence:}

Dr. Kanika. R. Kalyani,

E-mail: kanika.kalyani@gmail.com

(C) 2014 Kalyani KR et al. This is an open-access article distributed under the terms of the Creative Commons Attribution Non-Commercial License, which permits unrestricted non-commercial use, distribution, and reproduction in any medium, provided the original work is properly cited.

\begin{abstract}
Background: Gestational diabetes mellitus (GDM) is characterised by carbohydrate intolerance of varying severity with onset or first recognition during pregnancy. GDM is an important public health problem in India.

Method: The present study was carried out in 300 antenatal women. Fasting blood glucose was measured after which they were given $75 \mathrm{~g}$ oral glucose and plasma glucose was estimated at $2 \mathrm{~h}$. Patients with plasma glucose $>140 \mathrm{mg} / \mathrm{dl}$ were labelled as GDM. Thus WHO criteria were used for diagnosing GDM. Data was collected from all subjects on demographic characteristics, socioeconomic status, education level, parity, family history of diabetes and/or hypertension, BMI, etc. and pregnancy outcome was studied.

Results: Prevalence of GDM was found to be $8.33 \%$. Gestational diabetes mellitus was found to be significantly associated with age, parity, BMI, socioeconomic status, education level and was also found to be associated with adverse pregnancy outcomes.

Conclusion: GDM adversely affects maternal and fetal outcomes and its prevalence is steadily rising. Appropriate interventions are required for its control.
\end{abstract}

Keywords: Gestational diabetes mellitus, WHO OGTT, Prevalence

\section{INTRODUCTION}

The maternal metabolic adaptation maintains the mean fasting plasma glucose of $74.5 \pm 11 \mathrm{mg} / \mathrm{dl}$ and the post prandial peak of $108.7 \pm 16.9 \mathrm{mg} / \mathrm{dl}$. $^{1}$ The fine tuning of glycaemic level during pregnancy is possible due to the compensatory hyperinsulinaemia, as the normal pregnancy is characterised by insulin resistance. A pregnant woman who is not able to increase her insulin secretion to overcome the insulin resistance that occurs even during normal pregnancy develops gestational diabetes. Gestational diabetes mellitus (GDM) is characterised by carbohydrate intolerance of varying severity with onset or first recognition during pregnancy. ${ }^{2}$
A major challenge in evaluating the evidence on GDM screening is the range of adverse maternal and neonatal outcomes associated with untreated GDM. And the importance of GDM is that two generations are at risk of developing diabetes in the future. Although GDM is asymptomatic, the consequences may be substantial. The 2003 United States Preventive Services Task Force (USPSTF) evidence review suggested that hyperglycaemia's impact on adverse maternal and fetal outcomes is probably continuous. ${ }^{3}$

Prior to the discovery of insulin in 1921 by Frederic Banting and Charles Best, women with DM rarely became pregnant, and those who did, experienced a high incidence of maternal and fetal abnormality. Women with 
GDM have a greater incidence of preeclampsia which affects $10-25 \%$ of all pregnant diabetics. There is also a higher incidence of chorioamnionitis and postpartum endometritis, postpartum bleeding due to uterine over distension which is due to the macrosomic baby. More of women with GDM undergo caesarean sections and instrumental deliveries with more incidence of shoulder dystocia.

The consequences of GDM to the fetus are more serious than those to the mother. Amongst the fetal effects, the frequency of congenital anomalies is increased in women poorly controlled type $1 \mathrm{DM}$ and the incidence of fetal macrosomia is increased in women with GDM and DM type 2 . The fetus can get affected with various congenital anomalies (caudal regression syndrome, transposition of great vessels, VSD, ASD), hypoglycaemia, hyperviscosity syndrome, hyaline membrane disease, macrosomia, hypocalcaemia, apnoea, bradycardia, traumatic delivery and perinatal death. Pregnancy adversely affects DM by causing rapid progression of diabetic nephropathy, diabetic retinopathy, and increased risk of death in patients with diabetic cardiomyopathy.

The GDM is an important public health problem in India. In India, the prevalence of GDM is steadily increasing from $2 \%$ in 1982 to $7.2 \%$ in 1991 and $16.5 \%$ in 2002 . $^{4,5}$ The fact that GDM causes innumerable complications to the mother as well as the fetus and also increases the future risk, should alert the physicians the necessity to devote special attention to this segment of population in developing countries. Timely action taken in screening all pregnant women for glucose tolerance, achieving euglycaemia in them and ensuring adequate nutrition may prevent, in all probability, the vicious cycle of transmitting glucose tolerance from one generation to another.

The aim was to determine the prevalence of GDM, risk factors associated with it and the pregnancy outcomes.

\section{Objectives}

1. To determine the prevalence of GDM at a rural setup in Central India.

2. To determine the risk factors associated with GDM and its pregnancy outcome.

\section{METHODS}

The present study was conducted at the antenatal clinic in the Department of Obstetrics and Gynaecology at a rural tertiary hospital managed teaching hospital setting located in Sawangi (Meghe) in Wardha District of Maharashtra in Central India. A total of 300 women were screened for GDM using the WHO criteria. The inclusion criteria included all antenatal women attending the Acharya Vinoba Bhave Rural Hospital clinic while all patients with history of Diabetes Mellitus prior to onset of pregnancy were excluded. Patients were provided with detailed participant information and informed, witnessed, voluntary consent was taken from them in local vernacular. A standardised questionnaire was used and details pertaining to education, socioeconomic status, family history, obstetric history, past history was collected. Body mass index was also recorded. All women subjected to $75 \mathrm{~g}$ OGTT were advised to be on unrestricted diet, consuming at least 150 grams of carbohydrate daily, have usual activity for at least three days and come after an overnight fast of 10-12 hours. Fasting sample was then taken, 75 grams of glucose was given to them and plasma glucose was estimated at $2 \mathrm{hr}$ interval. GDM was diagnosed if plasma glucose was more than $140 \mathrm{gm} / \mathrm{dl}$.

\section{RESULTS}

A total of 300 subjects were evaluated for GDM. Out of 300 subjects, $25(8.33 \%)$ were diagnosed as GDM. The remaining formed the non GDM group. The mean age of the patients was $24.16+-3.63$ years. Table 1 shows that gestational diabetes was found to occur more in women above 25 years of age ( $\mathrm{p}$ value 0.0005 ). Since our study was carried out at a rural set up, majority (69.39\%) were from rural area. Most of the diabetics (64\%) belonged to the rural area followed by urban and semi urban area. Majority of the patients with GDM were second gravidas and above (19 out of $25,76 \%)$. On the other hand majority of subjects in the non GDM group were primigravidas showing a significant association between GDM and parity (p value 0.001). Mean gestational age of all the 300 subjects was $22.76 \pm 5.73$ weeks. GDM was diagnosed in a significant proportion of women between 13-20 weeks (28\%). Very few women with GDM had history of diabetes or hypertension in the family or in past or previous pregnancy. So it was found to be statistically insignificant. When data regarding educational status was taken, it was found that $61.67 \%$ women were educated till high school, intermediate or middle school. Most of the women with GDM (19 out of $25,76 \%$ ) were either postgraduates, professionals or graduates showing a significantly higher association between GDM and education level ( $\mathrm{p}$ value 0.00000000002217). Similarly, majority of women diagnosed to have GDM belonged to upper class and upper middle class (according to Kuppuswamy's classification) showing a correlation. Surprisingly, in the present study, there was not much association seen between GDM and history of abortions and intrauterine deaths. 96\% women who had GDM had their Body Mass Index (BMI) >30 showing a significant correlation between BMI and GDM. Mean BMI was higher in women with GDM (34.34) than non GDM (24.31).

Pregnancy outcomes of women with and without GDM were also studied in terms of mode of delivery, neonatal complications, NICU admissions and birth weight of the baby. $56 \%$ of subjects diagnosed to have GDM underwent lower segment caesarean section as compared to only $31.27 \%$ amongst those not having GDM. Along with caesarean section rate, even instrumental delivery 
rate was higher in GDM women (12\% against $5.4 \%$ in the non GDM group). GDM was found to be significantly associated with neonatal complications especially respiratory distress syndrome (RDS) and hypoglycaemia. $21.2 \%$ women with GDM had their babies with RDS as against 9.4 in the non GDM group. Amongst 300 women, 238 had their babies without any complication whereas 62 women had their babies having some or the other complication leading to NICU (Neonatal Intensive Care Unit) admission. 56\% women belonging to GDM group had their babies admitted to NICU as compared to only $21.33 \%$ women of the non GDM group with babies requiring NICU admission. We had a macrosomia rate of $9.33 \%$ with $44 \%$ of macrosomic babies born to GDM mothers and only $6.18 \%$ macrosomic babies born to non GDM mothers showing a significant association. Also, the mean birth weight in women with GDM (3.1 kg) was higher than in women without GDM $(2.68 \mathrm{~kg})$.

Table 1: Distribution of patients according to population.

\begin{tabular}{|lllll|}
\hline Residence & Total & Percent & GDM & $\begin{array}{l}\text { No } \\
\text { GDM }\end{array}$ \\
\hline Rural & 204 & 69.39 & 16 & 188 \\
\hline Semiurban & 22 & 7.48 & 1 & 21 \\
\hline Urban & 68 & 23.13 & 8 & 60 \\
\hline Total & 294 & 100 & 25 & 269 \\
\hline $\begin{array}{l}\text { Pearson } \\
\text { Chi2(2) } \\
1.4869\end{array}$ & & Pr $=0.475$ & & \\
\hline
\end{tabular}

Table 2: Distribution of patients according to their educational status.

\begin{tabular}{|lllll|}
\hline $\begin{array}{l}\text { Educational } \\
\text { status }\end{array}$ & Total & Percent & GDM & No GDM \\
\hline $\begin{array}{l}\text { Professionals/ } \\
\text { Postgraduates/ } \\
\text { Graduates }\end{array}$ & 64 & 21 & 19 & 44 \\
\hline $\begin{array}{l}\text { High School/ } \\
\text { Intermediate } \\
\text { /Middle } \\
\text { School }\end{array}$ & 185 & 61.67 & 4 & 181 \\
\hline $\begin{array}{l}\text { Primary } \\
\text { School }\end{array}$ & 38 & 12.67 & 0 & 38 \\
\hline $\begin{array}{l}\text { Illiterate } \\
\text { 14 }\end{array}$ & 4.67 & 2 & 12 \\
\hline $\begin{array}{l}\text { Total } \\
\text { Pearson }\end{array}$ & & 100 & 25 & 275 \\
\hline $\begin{array}{l}\text { Pear } 3 \text { ) } \\
\text { 52.6127 }\end{array}$ & & $\mathrm{P}=0.00000000002217$ \\
\hline
\end{tabular}

Table 3: Distribution of patients according to their class.

\begin{tabular}{|lllll|}
\hline Social Class & Total & Percent & GDM & $\begin{array}{l}\text { No } \\
\text { GDM }\end{array}$ \\
\hline Upper Class & 5 & 1.67 & 5 & 0 \\
\hline Upper Middle & 78 & 26.09 & 14 & 64 \\
\hline Lower Middle & 94 & 31.44 & 2 & 92 \\
\hline Upper Lower & 62 & 20.74 & 2 & 60 \\
\hline Lower & 60 & 20.07 & 2 & 58 \\
\hline Total & 299 & 100 & 25 & 274 \\
\hline $\begin{array}{l}\text { Pearson chi2(4) } \\
\text { =73.0381 }\end{array}$ & & $\mathrm{P}=0.000000000000005179$ \\
\hline
\end{tabular}

Table 4: Distribution of patients according to BMI $\left(\mathrm{kg} / \mathrm{m}^{2}\right)$.

\begin{tabular}{|lllll|}
\hline $\begin{array}{l}\text { Body Mass } \\
\text { Index }\end{array}$ & Total & Percent & GDM & $\begin{array}{l}\text { No } \\
\text { GDM }\end{array}$ \\
\hline less than 20 & 44 & 14.67 & 0 & 44 \\
\hline $20-25$ & 109 & 36.33 & 1 & 108 \\
\hline $25-30$ & 113 & 37.67 & 5 & 108 \\
\hline Above 30 & 34 & 11.33 & 19 & 15 \\
\hline Total & 300 & 100 & 25 & 275 \\
\hline Average & $\mathbf{2 5 . 1 5}$ & & $\mathbf{3 4 . 3 4}$ & $\mathbf{2 4 . 3 1 2 3 6}$ \\
\hline SD & $\mathbf{5 . 2 8}$ & & $\mathbf{4 . 9 2}$ & $\mathbf{4 . 4 6}$ \\
\hline $\begin{array}{l}\text { Pearson chi2(3) } \\
=114.7382\end{array}$ & & $\mathrm{P}=1.048$ & E- 24 & \\
\hline
\end{tabular}

Table 5: Distribution of patients according to mode of delivery.

\begin{tabular}{|lll|ll|}
\hline $\begin{array}{l}\text { Mode of } \\
\text { Delivery }\end{array}$ & Total & Percent & GDM & $\begin{array}{l}\text { No } \\
\text { GDM }\end{array}$ \\
\hline $\begin{array}{l}\text { Forceps } \\
\text { Delivery }\end{array}$ & 18 & 6 & 3 & 15 \\
\hline FTND & 180 & 60 & 8 & 172 \\
\hline LSCS & 100 & 33.33 & 14 & 86 \\
\hline $\begin{array}{l}\text { Preterm } \\
\text { Vaginal } \\
\text { Delivery }\end{array}$ & 1 & 0.33 & 0 & 1 \\
\hline VBAC & 1 & 0.33 & 0 & 1 \\
\hline Total & 300 & 100 & 25 & 275 \\
\hline $\begin{array}{l}\text { Pearson } \\
\text { Chi2(4) } \\
9.5855\end{array}$ & & $\mathrm{P}=0.048$ & & \\
\hline
\end{tabular}


Table 6: Distribution of patients according to neonatal complications.

\begin{tabular}{|lll|ll|}
\hline $\begin{array}{l}\text { Neonatal } \\
\text { Complications }\end{array}$ & Total & Percent & GDM & $\begin{array}{l}\text { No } \\
\text { GDM }\end{array}$ \\
\hline None & 233 & 77.67 & 9 & 224 \\
\hline For Observation & 2 & 0.67 & 2 & 0 \\
\hline Hyperbilirubinaemia & 6 & 2 & 0 & 6 \\
\hline $\begin{array}{l}\text { Hyperbilirubinaemia, } \\
\text { Hyperglycemia }\end{array}$ & 1 & 0.33 & 1 & 0 \\
\hline Hypoglycaemia & 7 & 2.33 & 4 & 3 \\
\hline Low Birth Weight & 5 & 1.67 & 0 & 5 \\
\hline $\begin{array}{l}\text { Meconium Stained } \\
\text { Liquor }\end{array}$ & 10 & 3.33 & 2 & 8 \\
\hline $\begin{array}{l}\text { Prematurity With } \\
\text { Low Birth Weight }\end{array}$ & 2 & 0.67 & 0 & 2 \\
\hline Preterm Delivery & 1 & 0.33 & 0 & 1 \\
\hline Respiratory Distress & 33 & 11 & 7 & 26 \\
\hline Total & 300 & 100 & 25 & 275 \\
\hline $\begin{array}{l}\text { Pearson Chi2(9) }= \\
71.1474\end{array}$ & & $\mathrm{P}=0.00000000009067$ \\
\hline
\end{tabular}

Table 7: Distribution of patients according to NICU admissions.

\begin{tabular}{|lllll|}
\hline $\begin{array}{l}\text { NICU } \\
\text { Admissions }\end{array}$ & Total & Percent & GDM & $\begin{array}{l}\text { No } \\
\text { GDM }\end{array}$ \\
\hline Yes & 62 & 20.67 & 14 & 48 \\
\hline No & 238 & 79.33 & 11 & 227 \\
\hline Total & 300 & 100 & 25 & 275 \\
\hline $\begin{array}{l}\text { Pearson } \\
\text { Chi2(1) } \\
20.7669\end{array}$ & & P=0.000005187 & \\
\hline
\end{tabular}

Table 8: Distribution of patients according to the weight of the baby.

\begin{tabular}{|llllll|}
\hline $\begin{array}{l}\text { Baby } \\
\text { Weight } \\
\text { Kg) }\end{array}$ & Total & Percent & GDM & $\begin{array}{l}\text { No } \\
\text { GDM }\end{array}$ & P - Value \\
\hline$<2$ & 30 & 10 & 2 & 28 & $\begin{array}{l}\text { (GDM Vs } \\
\text { Go } \\
\text { GDM) }\end{array}$ \\
\hline $2.1-2.5$ & 67 & 22.33 & 4 & 63 & \\
\hline $2.6-3$ & 156 & 52 & 8 & 148 & \\
\hline$>3.1$ & 47 & 15.67 & 11 & 36 & \\
\hline Total & 300 & 100 & 25 & 275 & \\
\hline Mean & 2.72 & & 3.1 & 2.68 & 0.0039 \\
\hline SD & 0.45 & & 0.64 & 0.42 & 0.0008 \\
\hline Range & $1.5-4$ & & $2-4$ & $1.5-$ & \\
\hline
\end{tabular}

Table 9: Distribution of patients according to the weight of baby.

\begin{tabular}{|lllll|}
\hline $\begin{array}{l}\text { Baby } \\
\text { Weight }\end{array}$ & Total & Percent & GDM & $\begin{array}{l}\text { No } \\
\text { GDM }\end{array}$ \\
\hline Upto 3.5 & 272 & 90.97 & 14 & 258 \\
\hline 3.5 or more & 28 & 9.33 & 11 & 17 \\
\hline Total & 300 & 100 & 25 & 275 \\
\hline Average & 2.72 & & 3.1 & 2.68 \\
\hline SD & 0.45 & & 0.64 & 0.41 \\
\hline $\begin{array}{l}\text { Pearson } \\
\text { chi2(1) } \\
40.6124\end{array}$ & & P=0.0000000001856 & \\
\hline
\end{tabular}

\section{DISCUSSION}

Diabetes in pregnancy has severe consequences for perinatal morbidity and mortality. GDM prevalence has been reported variably from 1.4 to $14 \%$ worldwide and differently among racial and ethnic groups. ${ }^{6}$ Compared to European women, the prevalence of gestational diabetes has increased 11 fold in women from the Indian subcontinent. ${ }^{7}$ Das et al., in their study of 300 women, found 61 with positive screening. Out of them, 12 were diagnosed as gestational diabetics, $10(9.4 \%)$ belonged to high risk group. ${ }^{8}$ In India, Seshaiah et al (2004) reported a very high prevalence of $17.7 \%$ in the government maternity hospital. ${ }^{9}$ Wahi et al., (2011) from Jammu found prevalence rate of $6.94 \% .^{6}$

Zargar et al., 2004, from Kashmir in India reported the overall prevalence of GDM as $3.8 \%$. The GDM prevalence steadily increased with the age (from $1.7 \%$ in women below 25 years to $18 \%$ in women 35 years or older). ${ }^{10}$

Similarly, in the present study, GDM was diagnosed in 25 women out of $300(8.33 \%)$ which was almost similar to the prevalence found by Rajput et al., (2013) reported a prevalence of $7.1 \%$ in a study at Postgraduate Institute of Medical Sciences, Rohtak, Haryana based on the ADA criteria. $^{11}$

Nilofer et al., (2012) reported an incidence of $6 \%$ in women screened in Karnataka but they screened only high risk group.

Most subjects (56\%) women with gestational diabetes were above 25 years with mean age being $24.16 \pm 3.63$. In a study by Balaji V, Madhuri Balaji et al, ${ }^{12} 2011$, the mean maternal age of 1463 pregnant women was $23.60 \pm 3.32$ years. The mean age of pregnant women in the study by Badikillaya et al., 2013 was $22.8 \pm 3.2$ years. ${ }^{13}$ In the study by Nilofer et al, seven out of 9 patients with GDM $(77.77 \%)$ were above the age of 30 years. 
Even in a study by Kalra et al. in Rajasthan, ${ }^{14}$ compared with non GDM, GDM patients were older, with the mean ages of the groups two groups being $24.7 \pm 3.11$ years and $27.1 \pm 2.44$ years. Majority of our patients diagnosed with gestational diabetes were second gravidas and above (76\%). This was further supported by a study by Sharma et al. conducted in Jammu who stated that prevalence of GDM increased with multigravida. ${ }^{15}$ According to a study by Seshiah et al, ${ }^{9}$ the prevalence proportion of GDM increased with gravid, from $18.1 \%$ (confidence limits $14.38-22.29 \%$ ) in the primigravida to $25.8 \%$ (confidence limits: $11.86-44.61 \%$ ) for the gravidas $>4$.

In the present study, significantly higher incidence of GDM was observed with higher educational level. Similarly in the study by Rajput et al., $21.9 \%$ were professional, postgraduate or graduate, $61.3 \%$ were educated till high school, intermediate or middle school and $4.9 \%$ women were illiterate. Innes et al. ${ }^{16}$ (2002) had found an inverse association between the educational level of the pregnant woman and gestational diabetes mellitus. A significant association of gestational diabetes mellitus was seen with socioeconomic status in our study subjects. This association could be related to multiple factors such as higher maternal age, higher prepregnancy weight and BMI, more sedentary lifestyle in women of higher socioeconomic status. The study conducted by Rajput et al., also showed a significant association between higher socioeconomic status and GDM. ${ }^{11}$

Das et al. and Gomez et al. found that $25 \%$ and $50 \%$ of women with GDM had obesity. Similarly in our study, majority (24 out of $25,96 \%$ ) of patients who had gestational diabetes mellitus had BMI >25 with $76 \%$ being obese i.e. having $\mathrm{BMI}>30$ thereby showing a significant correlation between BMI and gestational diabetes mellitus.

According to the study by Sharma et al., ${ }^{15} \mathrm{BMI}>30$ was observed in 30 (64\%) GDM women and 130 (29.2\%) NGT women. In our study, more of caesarean section rate was found in gestational diabetics $(56 \%)$ than non gestational diabetics $(31.27 \%)$. In a study by Kalra et al., ${ }^{14} 79 \%$ of GDM women underwent caesarean delivery as compared to $30 \%$ non GDM having caesarean delivery. GDM was found to be significantly associated with neonatal complications especially respiratory distress syndrome and hypoglycaemia. In a study by Nilofer et al., ${ }^{17}$ at Karnataka, India, which used GCT and OGTT to diagnose GDM and followed up patients till delivery, it was found that out of 9 cases of GDM, only one baby had hyperbilirubinaemia and only one had hypoglycaemia. Hyperbilirubinaemia was defined as treatment with phototherapy after birth, or atleast one laboratory report of bilirubin level $\geq 20 \mathrm{mg} / \mathrm{dl}$, or readmission to hospital for hyperbilirubinaemia. In gestational diabetes, maternal hyperglycemia leads to fetal hyperglycemia which in turn causes hyperinsulinaemia and excessive somatic growth due to increased insulin. IGF1, IGF2, epidermal growth factor and leptin may play a role. We had a macrosomia rate of $9.33 \%$ with $44 \%$ of macrosomic babies born to GDM mothers. In non GDM subjects, 17 out of 275 (6.18\%) women had macrosomia. In a study by Mohamed Alkhatim Alsammani et al., the prevalence of fetal macrosomia was found to be $4.5 \%$ but this study used 4 $\mathrm{kg}$ as the cut off weight for considering it as macrosomia. It was $1.5 \%$ in USA which considered birth weight $>4.5$ $\mathrm{kg}$. In India, Ramachandran et al. conducted a study over south Indian women and noticed that macrosomia, premature deliveries are higher in GDM pregnancy than normal pregnancy.

Thus, GDM was found to be associated with multiple risk factors and adverse pregnancy outcomes.

\section{CONCLUSION}

To conclude, the present study reports $8.33 \%$ prevalence of GDM from a tertiary care hospital of Sawangi, Wardha in Central India. This rising prevalence highlights the importance of carrying out prevalence studies in different geographical regions of India to delineate the exact prevalence of GDM in the country. Women with GDM are at an increased risk for adverse obstetric and perinatal outcomes. Although eradication of GDM is impossible, we can definitely prevent its adverse effects on pregnancy outcome. With effective screening and management of GDM, from "the diabetes capital of the world", we (India) can claim to be the "Diabetes care capital of World." 18

\section{Funding: None \\ Conflict of interest: None declared \\ Ethical approval: Not required}

\section{REFERENCES}

1. Yogev Y, Chen R, Langer O, Hod M. Diurnal Glycemic profile characterization in non diabetic non obese subjects during the first trimester. The $37^{\text {th }}$ Annual Meeting of The Diabetes And Pregnancy Study Group, Myconos - Hellas: September, 2005.

2. Metzger BE, Coustan DR. Summary and recommendations of the Fourth International Workshop Conference on Gestational Diabetes Mellitus: The Organising Committee. Diabetes Care 1998; 21 Suppl 2;B161-7.

3. Brody SC, Harris R, Lohr K. Screening for gestational diabetes: A summary from the US Preventive Services Task Force. Obstet Gynecol 2003:101:380-392.

4. Agrawal S, Gupta AN. Gestational Diabetes. J Assoc Physicians India 1982;30:203-5.

5. Narendra J, Munichoodappa C, Gurudas A, Ramprasad AV, Madhav T, Vijayalakshmi, et al. Prevalence of glucose intolerance during pregnancy. Int J Diab Dev Countries 1991;11:2-4. 
6. Wahi P, Dogra V, Jandial K, et al. Prevalence of gestational diabetes mellitus (GDM) and its outcomes in Jammu region. J Assoc Physicians India. 2011 Apr;59:227-30.

7. Seshiah V, Das K, Balaji V, Joshi SR, Parikh MN, Gupta S. Gestational Diabetes Mellitus- Guidelines. J Assoc Physicians India 2006;54:622-8.

8. Das V, Kamra S, Mishra A. Screening for gestational diabetes and maternal and fetal outcome. J Obstet Gynaecol India 2004;54:449-51.

9. Seshiah V, Balaji V, Balaji MS, et al. Gestational Diabetes Mellitus in India. J Assoc Physicians India 2004;52:707-11.

10. Zargar AH, Sheikh MI, Bashir M, et al. Prevalence of gestational diabetes mellitus in Kashmiri women in Indian subcontinent. Diabetes Res Clin Pract 2004;66(2):139-45.

11. Rajput R, Yadav Y, Nanada S, Rajput M. Prevalence of gestational diabetes mellitus and associated risk factors at a tertiary care hospital in Haryana. Indian J Med Red 2013;137:728-33.

12. Balaji V, Balaji $M$, Seshiah V. Inadequacy of fasting plasma glucose to diagnose gestational diabetes mellitus in Asian Indian women. Diabetes Res Clin Pract 2011;94(1):e21-e23.

13. Badikillaya VU, Adusumalli P, Venkata RG, Pernenkil S. Effectiveness of Diabetes in Pregnancy Study Group India Test (DIPSI) Diagnostic
Criterion in Detecting Gestational Diabetes Mellitus- a Pilot Study in a Rural Population. Indian J Basic and Applied Medical Research 2013;2:61461.

14. Kalra P, Kachhwaha CP, Singh HV. Prevalence of gestational diabetes mellitus and its outcome in western Rajasthan. Indian $\mathbf{J}$ Endocr Metab 2013;17:677-80.

15. Sharma K, Wahi P, Gupta A, Jandial K, Bhagat R, Gupta R, Gupta S, Singh J. Single Glucose Challenge Test Procedure for Diagnosis of Gestational Diabetes Mellitus: A Jammu Cohort Study. J Assoc Physicians India 2013;61:558-9.

16. Innes KE, Byers TE, Marshall JA, Baron A, Orleans M, Hamman RF. Association of a woman's own birth weight with subsequent risk for gestational diabetes. JAMA 2002;287:2534-41.

17. Nilofer AR, Raju VS, Dakshayini BR, Zaki SA. Screening in high risk group of gestational diabetes mellitus with its maternal and fetal outcomes. Indian J of Endocrinol Metab 2012;16:74-8.

18. Magon N. Gestational Diabetes Mellitus: Get, set, go from diabetes capital of the world to diabetes care capital of the world. Indian J Endocrinol Metab 2011;15:161-9.

DOI: $10.5455 / 2320-1770 . i j r \operatorname{cog} 20140344$

Cite this article as: Kalyani KR, Jajoo S,

Hariharan C, Samal S. Prevalence of gestational diabetes mellitus, its associated risk factors and pregnancy outcomes at a rural setup in Central India. Int J Reprod Contracept Obstet Gynecol 2014;3:219-24. 